\title{
ASPECTS REGARDING THE INTERDEPENDENCE BETWEEN AGGREGATED DEMAND AND OFFER
}

\author{
Lecturer PhD Student Maria Macriş, University of Petroşani, \\ e-mail: andradamacris@yahoo.com
}

\begin{abstract}
The paper focuses upon aggregated demand and offer and their interdependence as fundamental variables of competition market determining both the balance level of the general index of prices and the balance level of national production. Several forms of the correlation between aggregated demand and offer having significant consequences are also emphasized as well as the balance between them.
\end{abstract}

Keywords: aggregated demand and offer, general level of prices, national production.

JEL Codes: B22

Aggregated demand and offer, regarded in their interaction, represent the basic concepts of macro - economy and decisive elements in analyzing the production of goods and services, inflation, and economic growth as well as in elaborating economic policy. At the same time, the level of production and prices depend on the interaction of global demand and offer. The notions of global demand and offer are simultaneously and closely interdependently employed on all markets, namely: the market of goods and services, labor market, financial and monetary market. Subsequent references target global demand and offer on the market of goods and services.

A. Aggregated (global) demand represents the total amount of the production of goods and services of a national economy demanded at a certain general level of prices during a certain period of time. The total amount of demanded production is considered to be a gross or net national product or a national income. Regarded from this point of view, global demand consists in the total amount of expenditures of a national economy in order to buy goods and services, at a certain general level of prices during a certain period, irrespective of their use (Ciucur, D., Gavrilă, I., Popescu, C-tin., 2001). Global demand is structured according to the following elements: population's expenditures with a view of buying goods; companies' expenditures with gross investments in fixed capital and stocks variation, out of accumulation and amortization; governmental expenditures with a view of buying consumer goods and investments goods out of budget incomes; foreign companies' expenditures of a certain country employed in order to pay exports (net exports $=$ exports - imports).

The dependence of aggregated demand on the general level of prices and on the amount of national production (G.N.P.) determining available incomes to be spend in order to buy goods and services displays its function as a descendant curve as compared with price and as an ascendant curve as compared with national production (G.N.P.). Accordingly, the factors of the evolution of global demand are the evolution of the general level of prices and the evolution of incomes. As a consequence, aggregated demand increases when the general level of prices decreases and diminishes when the general level of prices grows; the general level of prices is calculated as a ponderate mean of the prices of all consumer goods and services produced at a certain moment by the economy.

World practice has shown that, irrespective of country, the general index of prices, at its best, can be stable or relatively stable; yet, its general tendency is to grow. When the general level of prices increases the buying capacity of the national currency decreases; accordingly, available 
nominal income is spent in order to buy smaller amounts of goods and services; this fact has as a consequence the decrease of the amount of aggregated demand, that is its contraction, the diminishing of the demand of products and services created on the national territory and the increase of the demand for import products and services which are less expensive than native goods. As a result, the main companies are going to target such a direction. Consequently, the population spends more money in order to buy import goods and services from abroad, the companies increase their expenditures in order to buy capital goods from abroad, and the government uses a larger part of budget incomes with a view of buying import consumer and investment goods.

The above data emphasize the fact the unjustified and uncontrolled increase of the general index of prices determines both the discouragement of national production and investments that are more expensive due to the increase of interest rate and of the importance paid to the external financing sources of the investment process. When the general level of prices is stable aggregated demand increases or decreases according to the changes occurring on the market under the influence of several factors among which the most significant are the following ones: government's economic policy, the general condition of world economy, the previsions of consumer and investing companies. The evolution of aggregated demand under the influence of the change of the general level of prices or as a result of demand terms can be graphically displayed in Figure no.1. The significance of the data is the following one: $\mathrm{CA}_{0}=$ curve of initial aggregated demand; $\mathrm{CA}_{1}=$ curve of aggregated demand increased as a result of the positive action of demand terms; $\mathrm{CA}_{2}=$ curve of decreased aggregated demand as a result of the negative action of demand terms; $\mathrm{P}=$ level of prices; $\mathrm{GNP}=$ gross national product; $\mathrm{i}_{\mathrm{p}}=$ index of prices; $\mathrm{CA}_{0}=$ curve of aggregated demand not altered by the influence of demand terms.

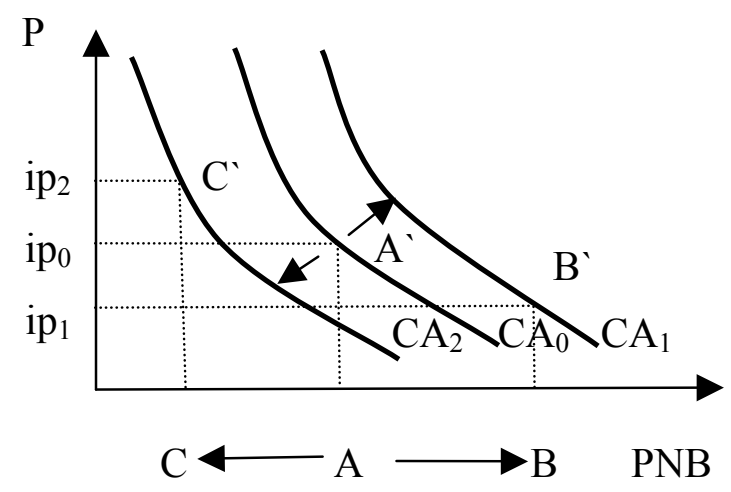

Fig. no. 1 - Curve of aggregated demand and its movement

B. Aggregated offer represents the total amount of the production of goods native and foreign companies offer to sell on the national market at a certain level of prices during a certain period of time. Aggregated offer, according to the goal of the analysis, can be considered as being the gross national product, the net national product or the national income, undergoing the correction of net exports. The level of aggregated offer of goods and services primarily depends on the general level of prices; the relation between the two variables is a direct one. Theoretically, the tendencies of the general level of prices can be increasing, decreasing or maintaining the same level. When the general index of prices decreases, aggregated offer diminishes; when it increases, aggregated offer also grows. When the general level of prices is relatively constant, aggregated offer is influenced by a series of factors, among which: the cost of productive factors per national economy, the amount of production factors attracted and employed by the national economy, the 
efficiency of productive factors. The curve of aggregated offer and its movement is graphically displayed in Figure no. 2. The significance of the data is as follows: $\mathrm{Oa}_{0}=$ curve of initial aggregated offer not affected by enumerated factors; $\mathrm{Oa}_{1}=$ curve of the offer increased as a result of the positive action of offer terms; $\mathrm{Oa}_{2}=$ curve of aggregated decreased offer as a result of the negative action of offer terms; P = level of prices; GNP, NNP or NI - gross national product, net national product or national income; $\mathrm{i}_{\mathrm{p}}=$ indices of prices.

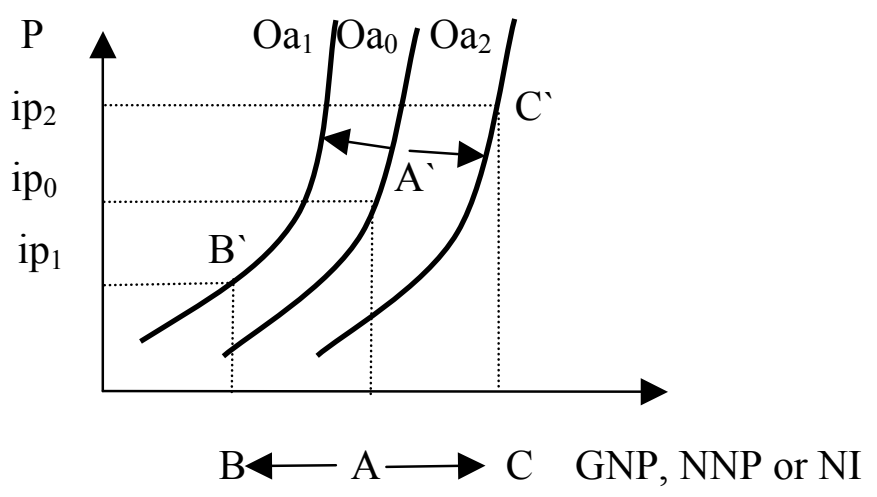

Fig. no. 2 - Curve of aggregated offer and its movement.

C. The balance between aggregated demand and aggregated offer. As fundamental variables of competition market, aggregated demand and aggregated offer, due to their interaction, determine both the balance level of the general index of prices and the balance level of national production. Accordingly, the function of aggregated demand, expressed by a descendant convex curve, and the function of aggregated offer, expressed by an ascendant convex curve, intersect; their intersection point, projected on the axis of prices, reflects the balance level of the general index of prices; its projection on the axis of national production emphasizes the equality between the offered quantity and the demanded quantity of national production. The balance between aggregated demand and offer is graphically displayed in Figure no. 3. The significance of the data is as follows: $\mathrm{I}_{\mathrm{g}} \mathrm{P}=$ general index of prices; $\mathrm{Q}=$ national production; $\mathrm{CA}=$ aggregated demand; $\mathrm{OA}$ $=$ aggregated offer; $\mathrm{E}=$ balance point between aggregated demand and offer.

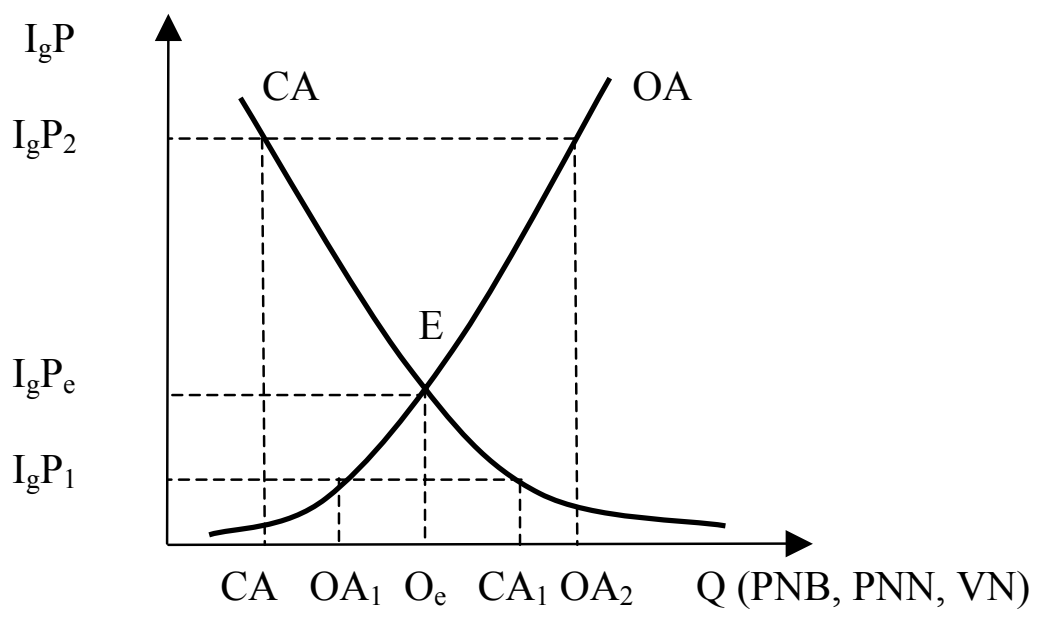

Fig. no. 3 - Balance between aggregated demand and offer

One can notice that a lower level of the general index of prices determines a low aggregated offer and a high aggregated demand. The increase of the general index of prices determines the 
decrease of aggregated demand and the increase of aggregated offer. When national economy is a functional market economy witnessing a period of prosperity, competition mechanism makes the general index of prices stable, namely makes it undergo minimal variations round the balance index of prices. Consequently, small variations of aggregated demand and offer are considered normal, non-inflationist macroeconomic phenomena.

The short term balance between aggregated demand and offer is absolutely accidental; the long term rule displays the deviations of the general index of prices as compared with the initial index which, through retroaction, changes national production. As a result, the notion of balance does not imply the absence of change as balance prices maintain only as long as the offer and demand that are to be found at their origin do not change. In other words, in case we would like to show why prices change then we should always look for the variations of the forces of aggregated offer and demand out of which initial prices emerged. In case we want to know whether demand or offer settles prices then the answer is the one given by the economist A. Marshall (Băcescu, M., Cărbunaru-Băcescu, A., 1998) "both of them settle prices simultaneously as the two arms of a pair of scissors cut". Prices are always determined by the intersection of the curves of demand and offer; practice has shown that, on a short term, the changes of aggregated demand are the most significant ones in determining prices variations; on a long term, the prevailing elements of prices evolution are the changes of aggregated offer.

D. Specialized works (Băbeanu, M., 2005) emphasized a series of forms of manifestation of the correlations between aggregated demand and offer; the following four are the most known:

a) When aggregated demand does not change, and aggregated offer increases offer's curve moves towards right; the general index of prices diminishes, balance quantities of demand and offer increase (this aspect shows that all effects are positive and the increase of aggregated offer is a priority element of macroeconomic policy);

b) When aggregated demand does not change, and aggregated offer decreases the general index of prices grows; balance quantities diminish, the prices of productive factors increase, production costs increase, prices grow (all these determine an excess of demand having consequences upon the non-controlled growth of prices);

c) When aggregated offer does not change, and aggregated demand grows as compared with balance level the general level of prices increases and national production increases; consumers want to buy larger amounts of goods; companies invest more as anticipated profits increase; export opportunities also grow, and the government can spend more with a view of buying goods and services;

d) When aggregated offer is constant, and aggregated demand decreases the general level of prices and of real GNP is lower; consumers buy less, companies invest less; exports diminish, and, as a consequence, the government spends less in order to buy goods and services.

The analysis of the possible correlations between aggregated demand and aggregated offer emphasizes two atypical situations that have negative effects, namely: when aggregated demand surpasses aggregated offer quite significantly during a larger period of time, demand becomes inflationist; when aggregated offer significantly diminishes during a larger period of time as compared with aggregated demand, then the phenomenon of inflationist aggregated offer comes out.

Inflationist aggregated demand and offer are graphically displayed in Figures no. 4 and 5. 


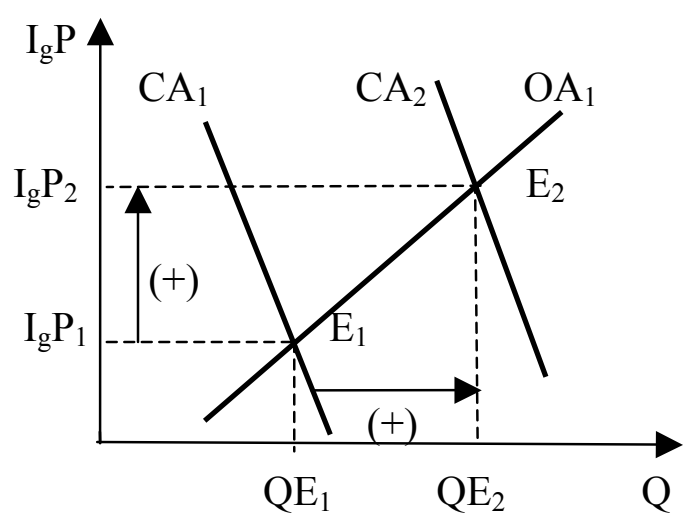

Fig. no. 4 - Inflationist aggregated demand

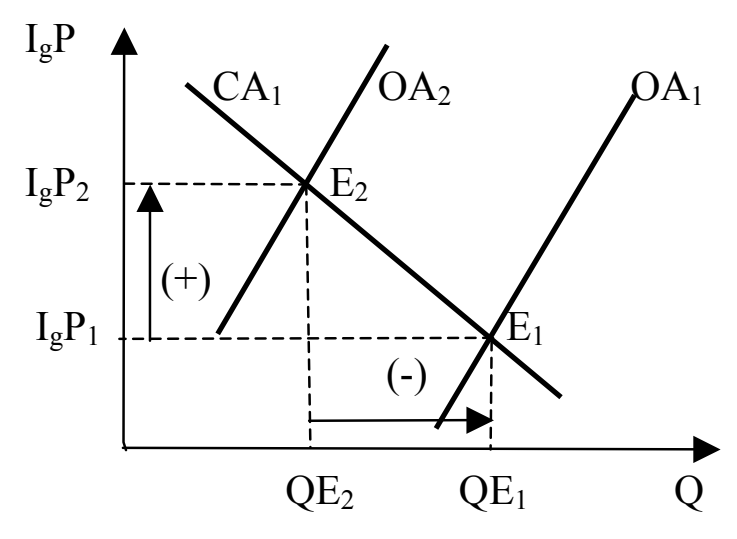

Fig. no. 5 - Inflationist aggregated offer

Figure no. 4 shows that aggregated offer $\left(\mathrm{OA}_{1}\right)$ is rigid; aggregated demand grows, moving towards right, from $\mathrm{CA}_{1}$ to $\mathrm{CA}_{2}$, and the index of prices grows from $\mathrm{I}_{\mathrm{g}} \mathrm{P}_{1}$ to $\mathrm{I}_{\mathrm{g}} \mathrm{P}_{2}$; the increase of the index of prices follows the growth of national production. Figure no.5 shows the phenomenon according to which aggregated demand is relatively constant, aggregated offer decreases from $\mathrm{OA}_{1}$ to $\mathrm{OA}_{2}$, the general index of prices grows from $\mathrm{I}_{\mathrm{g}} \mathrm{P}_{1}$ to $\mathrm{I}_{\mathrm{g}} \mathrm{P}_{2}$, more quickly than the amount of national production decreases.

We consider that the spontaneous mechanisms of the free market cannot rapidly do away with the disproportions that appear between aggregated demand and aggregated offer. National economy can be brought to a balance condition owing to the extremely positive intervening of the State through implementing adequate macroeconomic policies capable to determine the change of aggregated demand and offer, to influence the general level of prices and the GNP and to decrease inflation and unemployment. With these in view, a policy of aggregated demand becomes necessary and relies upon governmental measures able to increase demand; such a thing can be directly done through increasing State's expenditures with a view of buying investment and consumer goods from companies; it can also be indirectly done through diminishing taxes in order to encourage the companies and population to spend more for production and consumption. At the same time, a policy of aggregated offer is also necessary; it should rely upon stimulants capable of increasing production and productivity given both to companies and to population.

\section{References:}

1. Băbeanu, M. - Macroeconomie, University Text-Book, "Universitaria" Publishing House, Craiova, 2005.

2. Băcescu, M., Cărbunaru-Băcescu, A. - Microeconomie şi politici macroeconomice, All Educational Publishing House, Bucharest, 1998.

3. Ciucur, D., Gavrilă, I., Popescu, C-tin. - Economie, University Text-Book, Economic Publishing House, Bucharest, 2001.

4. Crețoiu, Gh., Cornescu, V., Bucur, I. - Economie, All Beck Publishing House, Bucharest, 2003

5. Genereux, J. - Economie politică. Macroeconomie în economia deschisă, Volume 3, All Beck Publishing House, 2000. 